\title{
Analysis of Goal Scored on Russia World Cup 2018
}

\author{
Halil Orbay Çobanoğlu \\ Correspondence: Halil Orbay Çobanoğlu, Muzaffer Çil Anadolu High School, Ministry of National Education, \\ Eskişehir, Turkey.
}

Received: January 10, 2019

Accepted: January 20, 2019

Online Published: January 28, 2019

doi:10.11114/jets.v7i2.3998

URL: https://doi.org/10.11114/jets.v7i2.3998

\begin{abstract}
The aim of the research was to analyze the goals scored in Russia World Cup 2018.

The sample of this research was composed of 64 games played and 169 goals scored in the 2018 Russia World Cup. No goals were scored only in one competition. Because of 12 goals scored were own goals, 157 goals scored were analyzed on eleven different ways. The research data were collected e-analysis soccer programme. Frequency, average, standard deviation which were descriptive statistics were used for analysis of the research data.

Consequently it was observed that $61,14 \%$ of goals were scored in the 2 nd half of the matches and most of goals in the last 15 minutes of the matches, $63,69 \%$ of goals were scored after organized attack (open play), 38,59\% of goals were scored from penalty, $78,98 \%$ of goals were scored with foot shot, $72,61 \%$ of goals were scored with one touch, $84,71 \%$ of the goals were scored through the penalty zone and $60,50 \%$ of the goals were scored in 3rd zone which was determined in the penalty zone. Moreover, of the teams that scored first results showed that they won 71,42\% of the matches. Scorer's playing position was 32,48\% striker. Asist player's playing position was 44,03\% midfielder. 11,92\% of asist were passed from 9th zone which was determined outside the penalty zone.

The work guided the coaches to design real competition-like trainings and tailor the game style to the match situation. Coaches can also use this information to set goals for players and teams that specifically refer to offense and defense games. It is advisable to coach to use the 3rd zone set in the penalty zone for more goals and to use the 3rd zone in the penalty zone for more effective defense for fewer goals.
\end{abstract}

Keywords: soccer, goal analysis, goal scored, Russia World Cup 2018

\section{Introduction}

The importance of processes to measure game and player quality in football is growing. From one point of view, this is a natural result of industrialization. Today, not only the coaches of professional teams, but even the coaches of amateur teams want to know how many miles the players run. In particular, the statistical studies made from post-match images, that is, these data produced in time and thinking, have the power to influence team strategies and shed light on the future of football today and the future.

In the literature, there are many studies related to match analysis and goal analysis. While some of these studies were based on passes' number before the goal, some studies focused on the time when goals were scored, some of them had an impact on the outcome of the first goal (Hughes \& Franks, 2005; Yiannakos \& Armatas, 2006).

Some studies focused on the way the goals were formed and searched for goals scored as a result of organized attack games and set games, while others explored the area where the goals were scored and the goals scored (Jinshan, Xiakone, Yamanaka \& Matsumoto, 1993; Çobanoğlu \& Terekli, 2018).

Statistical analysis, such as any scientific process, is not a way to find the truth, but a way to approach it. One of the most important skills of coaches is the ability to observe and recall all critical events of a sporting performance. (Borrie, Jonsson \& Magnusson, 2002). Although the data used for this purpose comes from within the field, some are not yet measured, some will not be measured at all, some will be more affected by factors that develop outside the field. There is only one statistic in football that explains the score without mistake, which is the statistics of the ball that crosses the goal line, i.e. the number of goals. Parameters other than goals are not known to the expected goal, but can give clues to the team's understanding of the game.

In this study, it was aimed to analyze the goals of 2018 World Cup with regard to following new soccer trends. 


\section{Methods}

The sample of this research was composed of 64 games played and 169 goals scored in the 2018 Russia World Cup. Because of 12 goals scored were own goals, 157 goals scored were analyzed for eleven different performance indicators. Two researchers collected the research's data in the form of monitoring and taking notes. The following 11 performance indicators were analyzed:

1) Time of goal scored $(0-15,16-30,31-45+, 46-60,61-75,76-90+, 1$ st e.t. and 2 nd e.t. $)$

2) Effect of first goal on outcome (Win, Draw or Loss)

3) Play type (Open or Set play)

4) Set-Play type (Penalty, Free Kick, Corner, Throw in)

5) Actions that lead to the goal (One touch, Control+shot, Control+dribble+shot)

6) Shot type (Right foot, left foot, head)

7) Goal zone (inside or outside the penalty area)

8) Goal zone (1, 2, 3, 4, 5, 6, 7, 8, 9, 10, 11, 12, 13, 14, 15, 16)

9) Playing position of scorer (Striker, Winger, Midfielder, Defender)

10) Asist zone (1, 2, 3, 4, 5, 6, 7, 8, 9, 10, 11, 12, 13, 14, 15, 16, 17)

11) Playing position of assist's player (Striker, Winger, Midfielder, Defender)

Statistical Analysis

Frequency, average and standard deviation which were descriptive statistics were used in research. Inter-rater reliability of individual observations was calculated to ensure the quality of the observation system. 1.00 reliability index was observed (intraclass correlation coefficient and kappa index). Data were analyzed by using SPSS 24 Statistical Program.

\section{Results}

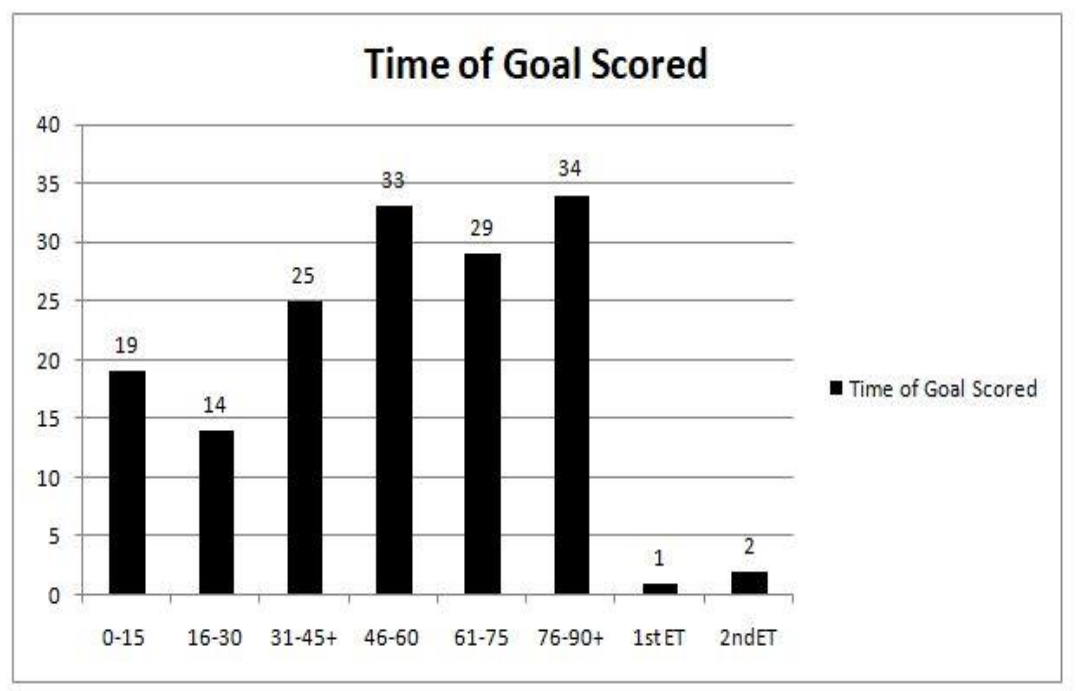

Figure 1. Time of goal scored

Consequently it was seen that $61,14 \%$ (96) of goals were scored in the 2nd half of the games and most of golas (34 goals) in the last 15 minutes, 


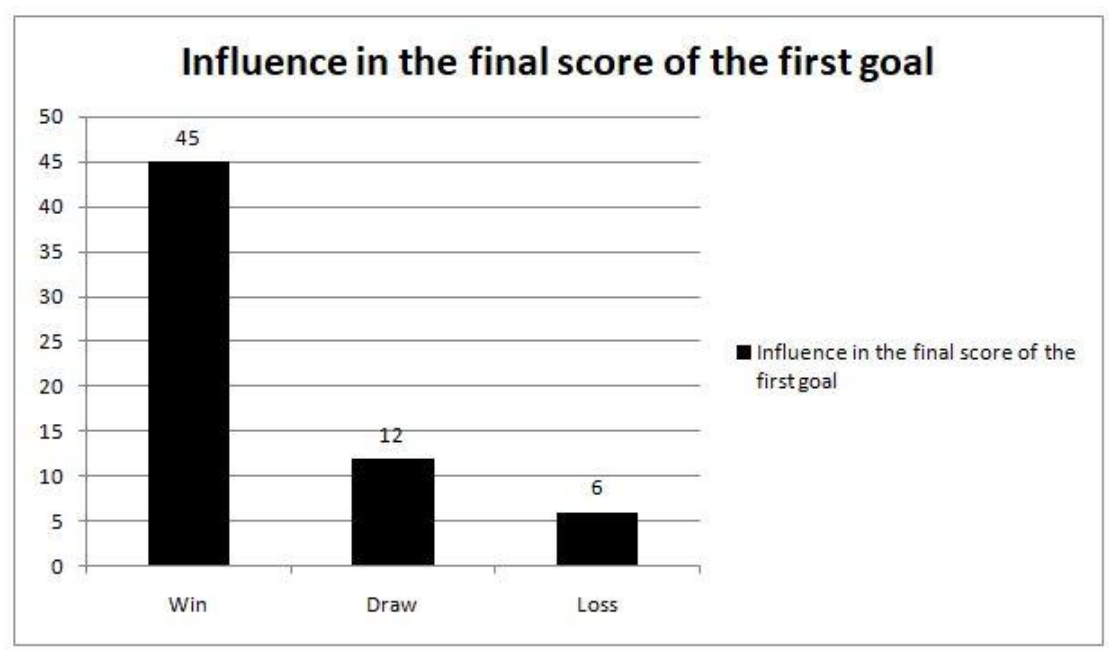

Figure 2. Effect of first goal on outcome

When Figure 2 examined, it was seen that the teams which scored first results showed that they won $71,42 \%(45)$ of the matches.

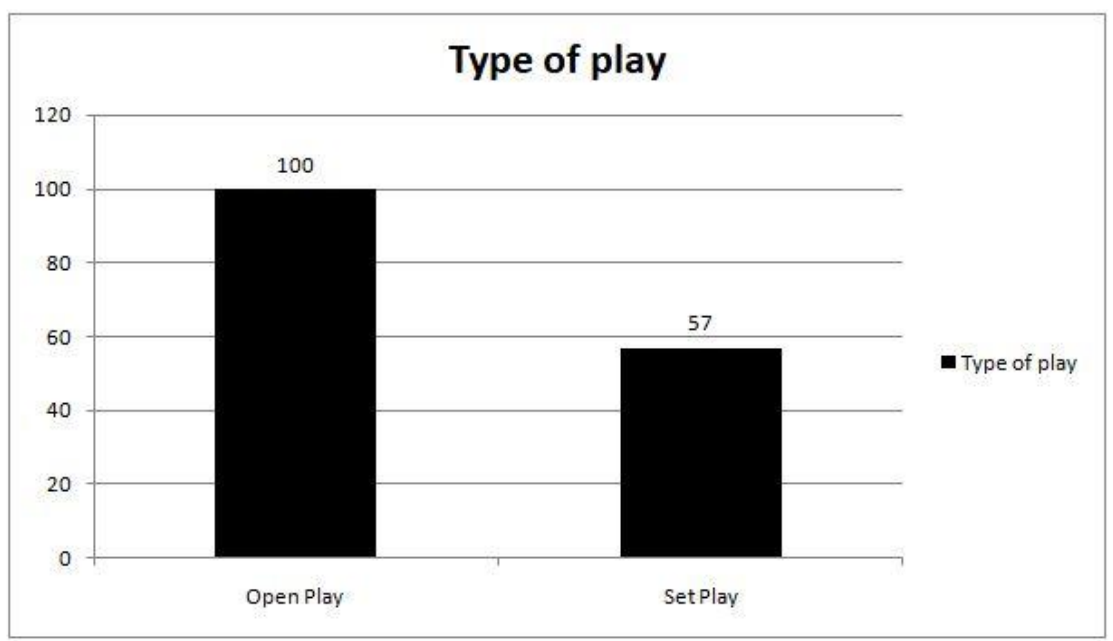

Figure 3. Play Type

When Figure 3 examined, it was seen that 63,69\% (100) of goals were scored after organized attack (open play) and $36,30 \%$ (57) of goals were scored after set play.

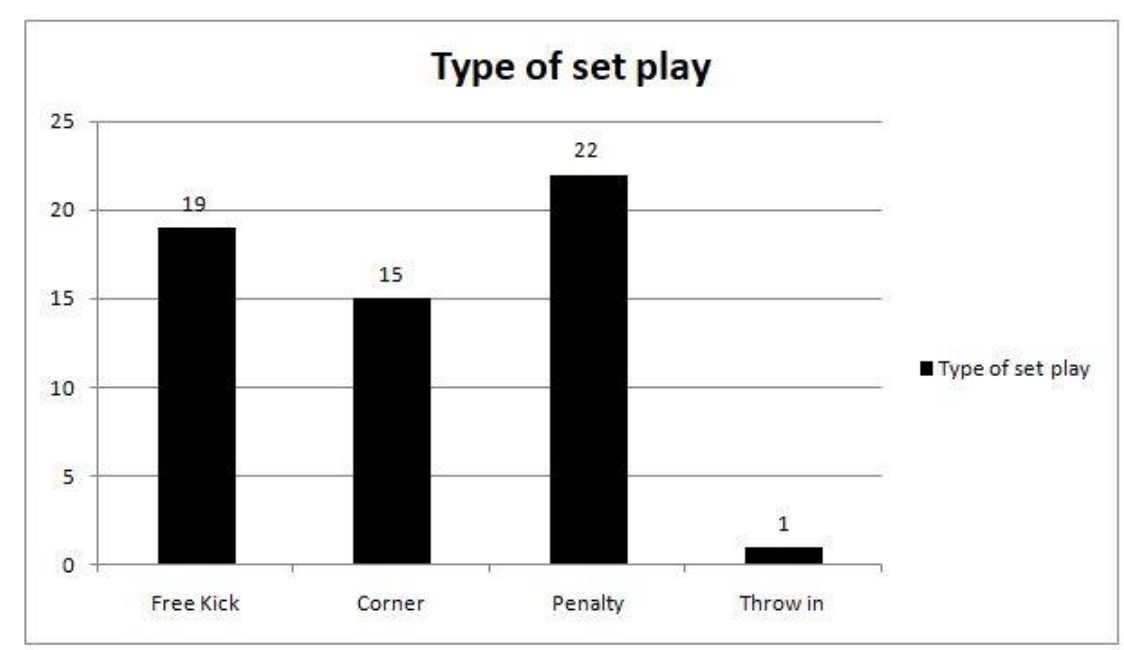

Figure 4. Set-Play Type 
When Figure 4 examined, it was seen that 33,33\% (19) of goals were scored from free kick, 26,31\% (15) of goals were scored from corner and $38,59 \%$ (22) of goals were scored from penalty.

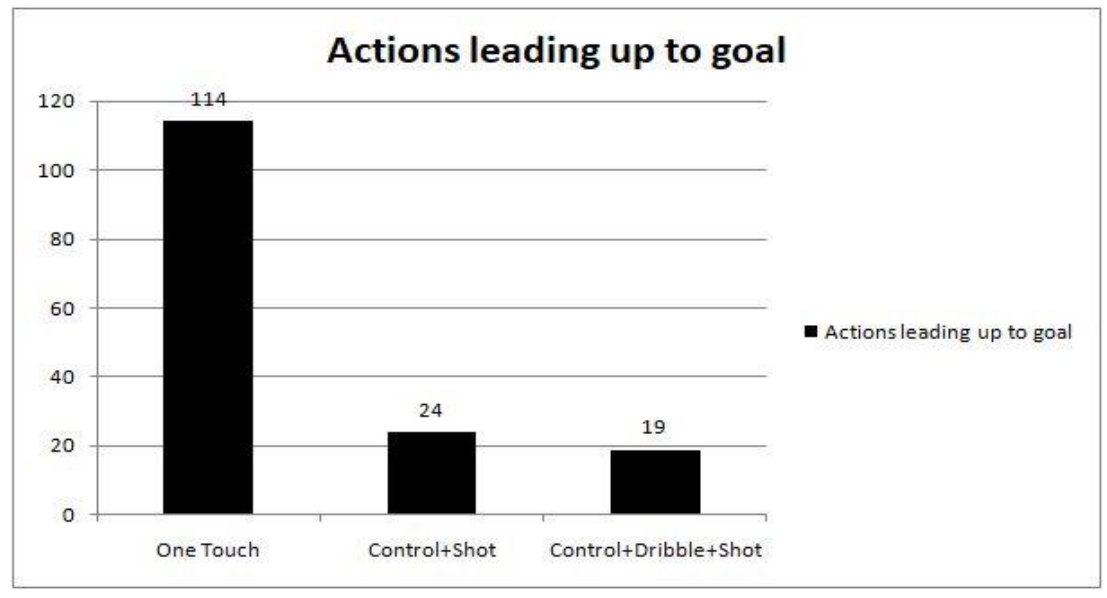

Figure 5. Actions that lead to the goal

When Figure 5 examined, it was seen that 72,61\% (114) of goals were scored with one touch, 15,28\% (24) of goals were scored with control+shot.

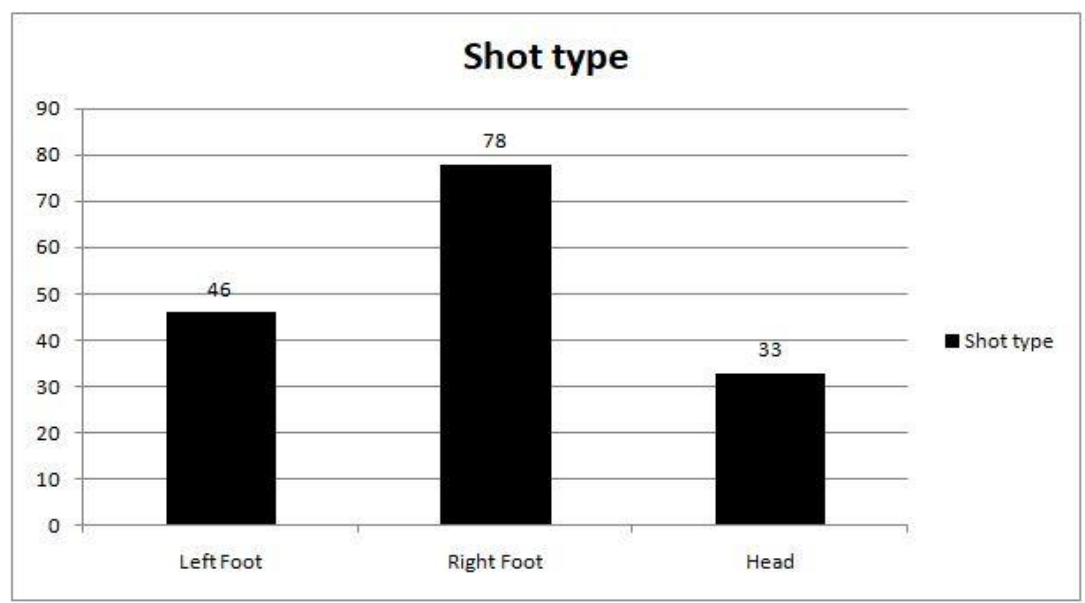

Figure 6. Shot type

When Figure 6 examined, it was seen that 49,68\% (78) of goals were scored with right foot, 29,29\% (46) of goals were scored with left foot and $21,01 \%$ (33) of goals were scored with head.

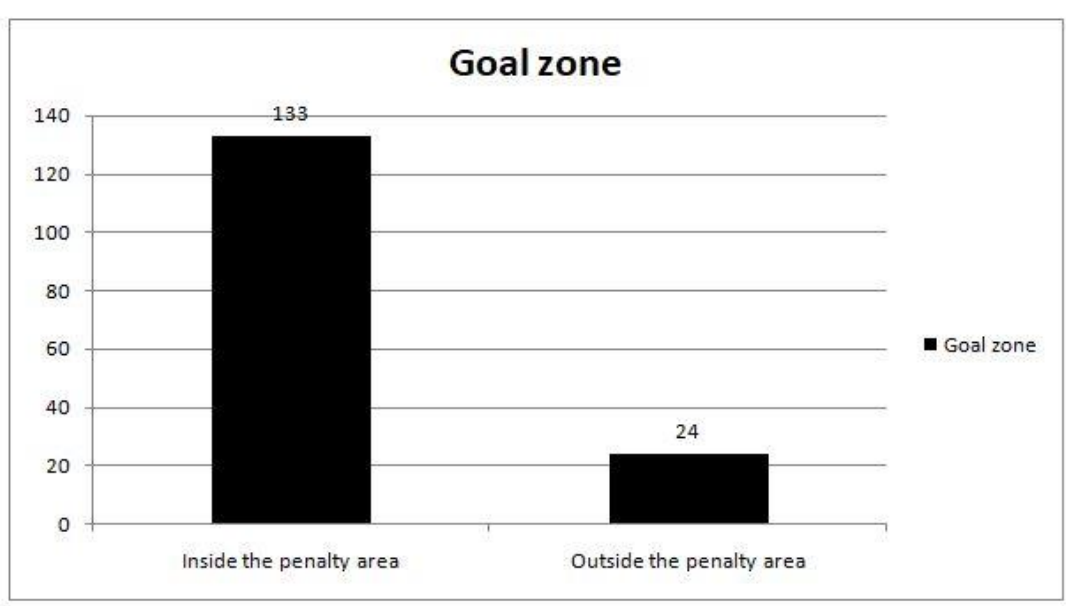

Figure 7. Goal zone

When Figure 7 examined, it was seen that $84,71 \%$ (133) of the goals were scored inside the penalty zone and $15,28 \%$ 
(24) of the goals outside the penalty zone.

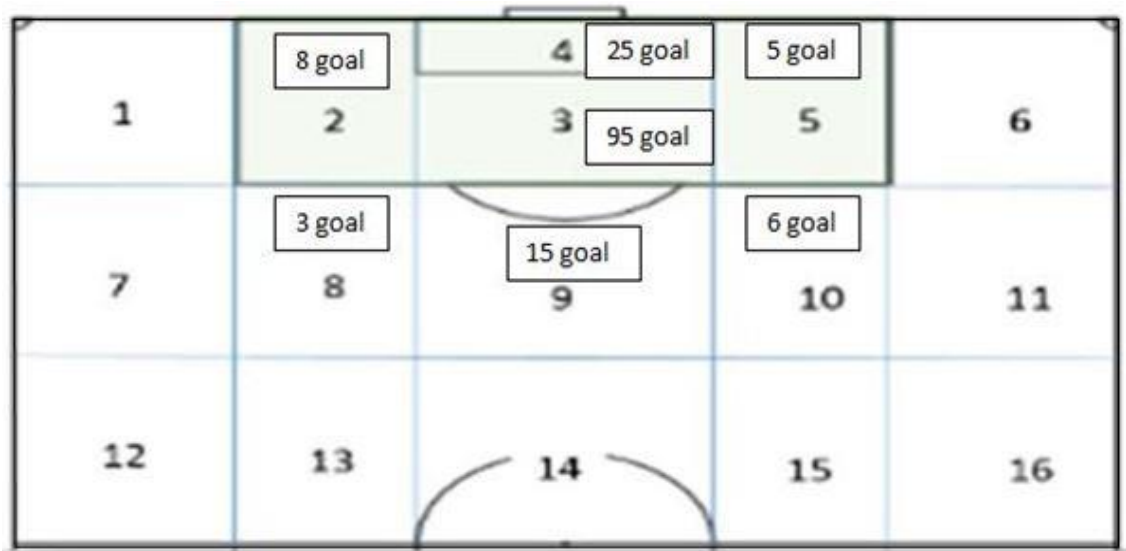

Figure 8. Goal zone

When Figure 8 examined, it was seen that 60,50\% (95) of the goals were scored in 3rd zone and 15,92\% (25) of the goals were scored in 4 th zone which were determined inside the penalty area. 9,55\% (15) of the goals were scored in 9 th zone which were determined outside the penalty area.

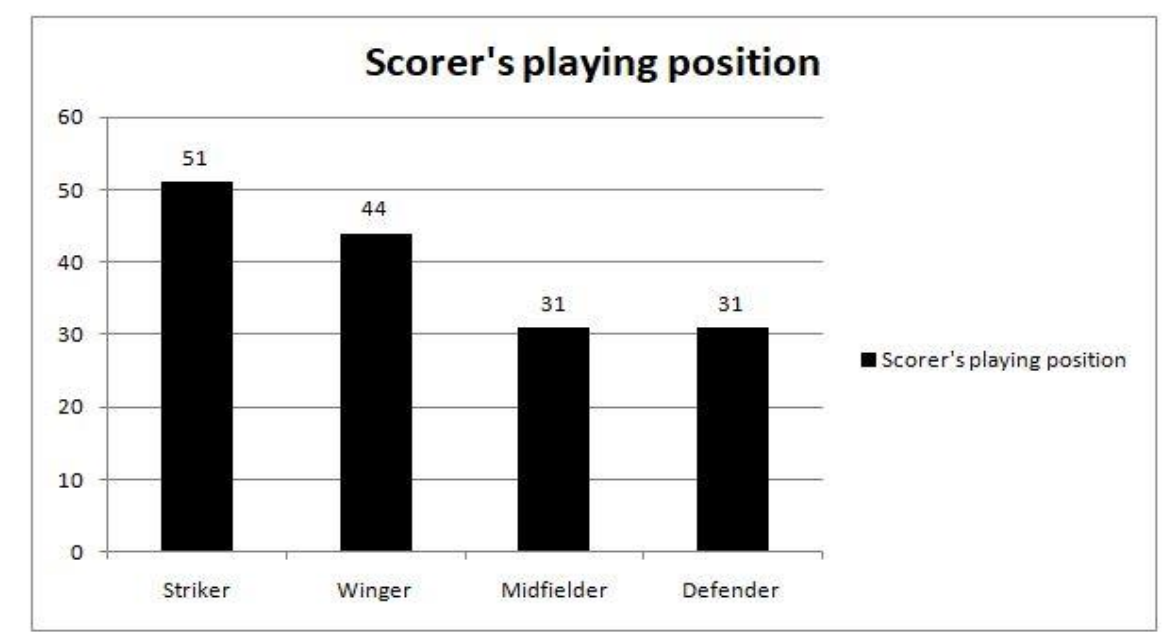

Figure 9. Playing position of scorer

When Figure 9 examined, it was observed that scorer's playing position were 32,48\% (51) striker, 28,02\% (44) winger, $19,74 \%$ (31) midfielder and $19,74 \%$ (31) defender.

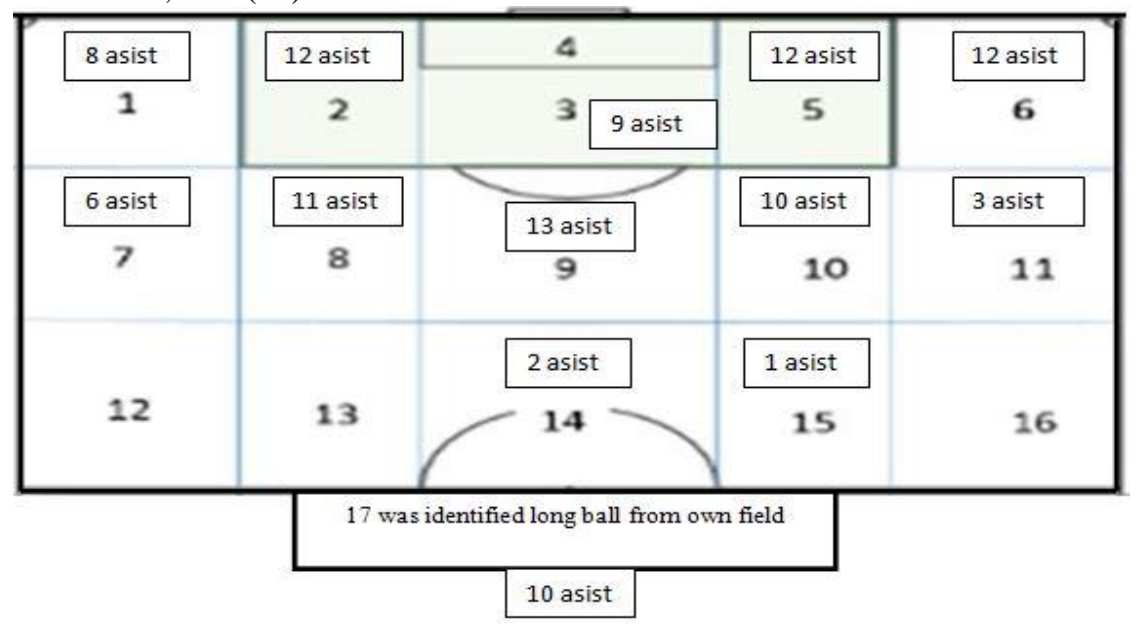

Figure 10. Asist's zone

When Figure 10 examined, it was seen that 11,92\% (13) of asist were passed from 9th zone which was determined 
outside the penalty zone, $11 \%$ (12) of asist were passed from 2nd zone and $11 \%$ (12) of asist were passed from 5th zone which were determined inside the penalty zone.

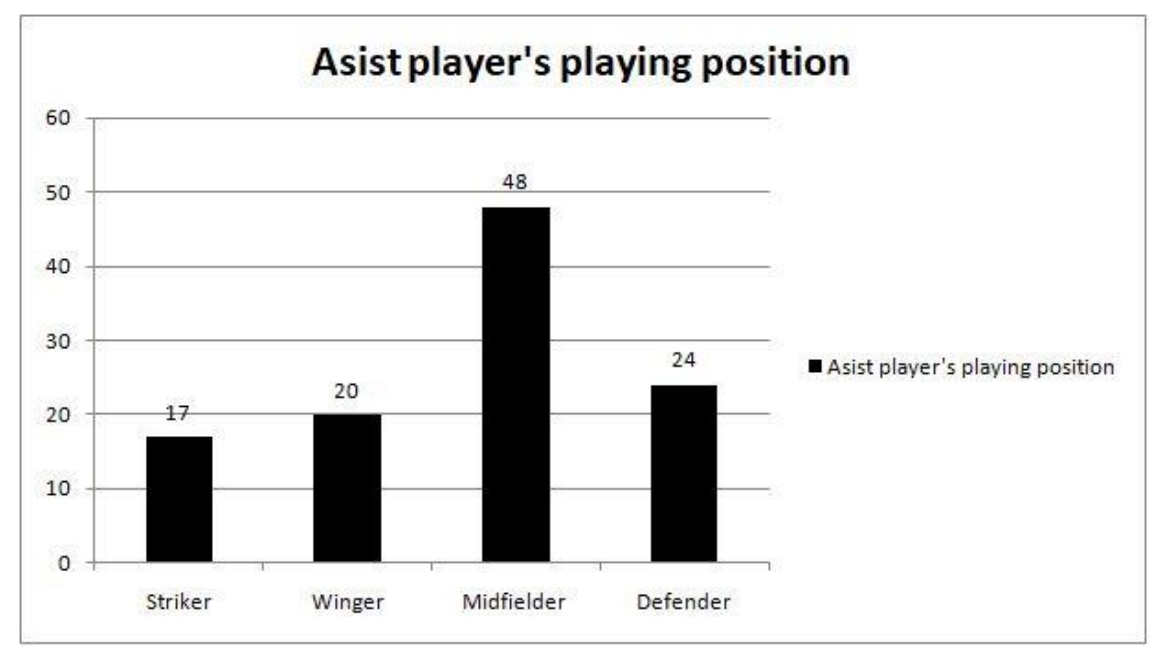

Figure 11. Playing position of assist's player

When Figure 11 examined, it was seen that asist player's playing position were 15,59\% (17) striker, 18,34\% (20) winger, $44,03 \%$ (48) midfielder and $22,01 \%$ (24) defender.

\section{Discussion}

The aim of the study was to analyze the goals scored in Russia World Cup 2018. Firstly, consequently it was seen that $61,14 \%$ (96) of goals were scored in the 2 nd half of the matches and most of them (34 goals) in the last 15 minutes. Leite (2013) in his study which aim was to analyze goals scored in Euro 2012 found that 44 goals (57.89\%) were scored in the second half of matches. Çobanoğlu \& Terekli (2018) in their study which aim was to analyze goals scored in Euro 2016 found that 66 goals were scored $(61,11 \%)$ in the second half of the matches. Armatas, Yiannakos \& Sileloglou (2007) in their study analyzed three World Cup and the results showed that most goals scored in the second half of the matches and scored 60.8\% (1998 World Cup), 59\% (2002 World Cup) and 52.5\% (2006 World Cup) of goals. Yiannis (2014) in his study (2014 World Cup Analysis) found that 98 goals were scored $(57,3 \%$ ) in the second half of the matches. Yiannakos \& Armatas (2006) in his study on the goals at Euro 2004, found that $57.4 \%$ of the goals were scored in the 2nd half of matches. And similarly Göral (2016) in his study which aim was to analyze goals scored in the U-20 World Cup 2013 found that 82 goals were scored $(53,94 \%)$ in the second half of the matches.

In this study it was seen that the teams which scored first, results showed that they won $71,42 \%$ (45) of the matches. Yiannis (2014) in his study which aim was to analyze goals scored in the 2014 World Cup found that the teams which scored first, results showed that they won 75,44\% (43) of the matches. Leite (2013) in his study emphasized that the teams which scored first, they won 70,97\% (22) of the matches. Pratas, Volossovitch \& Carita (2016) in their study examnied that 240 matches in Portuguese Premier League and they emphasized that which scored the first goal in the match won $70 \%$ of matches. In addition, many studies have highlighted the effect of the early goal on the final score (Jones \& Harwood, 2008; Olsen \& Larsen, 1997).

In this study it was seen that $63,69 \%$ (100) of goals were scored after organized attack (open play) and 36,30\% (57) of goals were scored after set play. And it was observed that 33,33\% (19) of goals were scored from free kick, 26,31\% (15) of goals were scored from corner and 38,59\% (22) of goals were scored from penalty. Mitrotasios \& Armatas (2014) in their study emphasized that most goals $(72,4 \%)$ were scored during open play in Euro 2012. Cerrah, Özer \& Bayram (2016) in their study they examined goals scored in Turkish Super League for five seasons and they emphasized that 2.594 goals $(71,78 \%)$ were scored after organized attack and 1.020 goals $(28,22 \%)$ were scored after set play.

In this study it was seen that $72,61 \%$ (114) of goals were scored with one touch, 15,28\% (24) of goals were scored with control+shot. Mitrotasios \& Armatas (2014) in their study emphasized that after the final pass, the scorer finished in most cases with one touch $(63,7 \%)$.

In this study it was seen that $49,68 \%$ (78) of goals were scored with right foot, $29,29 \%$ (46) of goals were scored with left foot and $21,01 \%$ (33) of goals were scored with head. In the other study it was seen that $42,6 \%$ (46) of goals were scored with right food, $33,3 \%$ (36) of goals were scored left foot and $24,1 \%$ (26) of goals were scored with head (Çebi, Elioz, İslamoğlu \& Yamak, 2016). 
In this study it was seen that $84,71 \%$ (133) of the goals were scored inside the penalty zone and $15,28 \%$ (24) of the goals outside the penalty zone. Yiannis (2014) in his study emphasized that most goals $(65,5 \%)$ was achieved through penalty zone too. Mitrotasios \& Armatas (2014) in their study emphasized that more than $90 \%$ of goals were scored from within the penalty area. Armatas \& Yiannakos (2010) in their study for 2006 World Cup Analysis emphasized that $83,4 \%$ of the goals were scored inside the penalty zone. In the other study for English Premier Leauge the researchers emphasized that $87 \%$ of the goals were scored inside the penalty zone (Wright, Atkins, Polman, Jones \& Lee, 2011).

In this study it was seen that $60,50 \%$ (95) of the goals were scored in 3rd zone and $15,92 \%$ (25) of the goals were scored in 4th zone which were determined inside the penalty zone. 9,55\% of the goals (15) were scored in the 9th region determined outside the penalty zone. And it was seen that scorer's playing position were $32,48 \%$ (51) striker, $28,02 \%$ (44) winger, 19,74\% (31) midfielder and 19,74\% (31) defender. Mitrotasios \& Armatas (2014) in their study found that $41,3 \%$ of goals were scored by strikers and $29,3 \%$ of goals by wingers too.

In this study it was seen that $11,92 \%$ (13) of asist were passed from 9th zone which was determined outside the penalty zone, $11 \%$ (12) of asist were passed from 2nd zone and $11 \%$ (12) of asist were passed from 5th zone which were determined inside the penalty zone. And it was seen that asist player's playing position were $15,59 \%$ (17) striker, $18,34 \%$ (20) winger, $44,03 \%$ (48) midfielder and $22,01 \%$ (24) defender.

\section{Conclusion}

The work guided the coaches to design real competition-like trainings and tailor the game style to the match situation. Coaches can also use this information to set goals for players and teams that specifically refer to offense and defense games. It is advisable to coach to use the 3rd zone set in the penalty area for more goals and to use the 3rd zone in the penalty area for more effective defense for fewer goals.

\section{References}

Armatas, V., \& Yiannakos, A. (2010). Analysis and evaluation of goals scored in 2006 World Cup. Journal of Sport \& Health Research, 2, 119-128.

Armatas, V., Yiannakos, A., \& Sileloglou, P. (2007). Relationship between time and goal scoring in soccer games: Analysis of three World Cups. International Journal of Performance Analysis in Sport, 7(2), 49-58. https://doi.org/10.1080/24748668.2007.11868396

Borrie, A., Jonsson, G. K., \& Magnusson, M. S. (2002). Temporal pattern analysis and its applicability in sport: an explanation and exemplar data. J Sports Sci. 20(10), 845-852. https://doi.org/10.1080/026404102320675675

Çebi, M., Elioz, M., İslamoğlu, İ., \& Yamak, B. (2016). 2016 European Football Championship Goal Analysis. ЖУРНАЛ НАУКОВИЙ ОГЛЯД, 10(31), 1-13.

Cerrah, A. O., Özer, B., \& Bayram, İ. (2016). Quantitative Analysis of Goals Scored from Set Pieces: Turkey Super League Application. Türkiye Klinikleri J. Sports Sci. 8(2), 37-45. https://doi.org/10.5336/sportsci.2016-50745

Çobanoğlu, H. O., \& Terekli, M. S. (2018). EURO 2016: Analysis of Goals Scored. Türkiye Klinikleri J. Sports Sci., 10(3), 123-9. https://doi.org/10.5336/sportsci.2018-61913

Göral, K. (2016). FIFA U-20 World Cup 2013: Analysis and Evaluation of Goals Scored. Revista Brasileira de Futsal e Futebol, 8(28), 29-38.

Hughes, M., \& Franks, I. (2005). Analysis of passing sequences, shots and goals in soccer. J Sports Sci., 23(5), 509-514. https://doi.org/10.1080/02640410410001716779

Jinshan, X., Xiakone, C., Yamanaka, K., \& Matsumoto, M. (1993). Analysis of the goals in the 14th World Cup. In: Reilly T, Clarys J, Stibbe A, Eds. Science \& Football II. 1st Ed. London: E \& F Spon; p.203-5.

Jones, M., \& Harwood, C. (2008). Psychological momentum within competitive soccer: Players' perspectives. Journal of Applied Sport Psychology, 20, 57-72. https://doi.org/10.1080/10413200701784841

Leite, W. A. A. (2013). Euro 2012: Analysis and Evaluation of Goals Scored. International Journal of Sports Science, 3(4), 102-106. https://doi.org/10.5923/j.sports.20130304.02.

Mitrotasios, M., \& Armatas, V. (2014). Analysis of Goal Scoring Patterns in the 2012 European Football Championship. The Sport Journal, January 16: 1-11.

Olsen, E., \& Larsen, O. (1997). Use of match analysis by coaches. In T. Reilly, J. Bangsbo, and M. Hughes (Eds.), Science and football III (pp. 209-220). London: E. and F. Spon.

Pratas, J. M., Volossovitch, A., \& Carita, A. I. (2016). The effect of performance indicators on the time the first goal is scored in football matches. International Journal of Performance Analysis in Sport, 16, 347-354. 
https://doi.org/10.1080/24748668.2016.11868891

Wright, C., Atkins, S., Polman, R., Jones, B., \& Lee, S. (2011). Factors associated with goals and goal scoring opportunities in professional soccer. International Journal of Performance Analysis in Sport, 11, 438-449. https://doi.org/10.1080/24748668.2011.11868563

Yiannakos, A., \& Armatas, V. (2006). Evaluation of the goal scoring patterns in European Championship in Portugal 2004. International Journal of Performance Analysis in Sport, $6(1)$, 178-188. https://doi.org/10.1080/24748668.2006.11868366

Yiannis, M. (2014). Analysis of goals scored in the 2014 World Cup Soccer tournament held in Brazil. International Journal of Sport Studies. 4(9), 1017-1026.

\section{Copyrights}

Copyright for this article is retained by the author(s), with first publication rights granted to the journal.

This is an open-access article distributed under the terms and conditions of the Creative Commons Attribution license which permits unrestricted use, distribution, and reproduction in any medium, provided the original work is properly cited. 